\title{
DESEMPENHO DA PRODUÇÃO DA CULTURA DE CANA-DE-AÇÚCAR NOS PRINCIPAIS ESTADOS PRODUTORES
}

\author{
PERFORMANCE OF SUGARCANE CULTURE PRODUCTION IN THE MAIN \\ PRODUCING STATES \&
DESEMPEÑO DEL CULTIVO DE CAÑA DE AZÚCAR EN LOS PRINCIPALES ESTADOS PRODUCTORES \&

Recebido em: 11/09/2021 - Aprovado em: 04/10/2021 - Publicado em: 13/10/2021

doi) http://dx.doi.org/10.18011/bioeng2021v15n2p303-317

\begin{abstract}
Lázaro Quintino Alves' (lazaro.alves@aluno.unifenas.br)
Petrus Narciso Franco'1 (petrus.franco@aluno.unifenas.br)

Willian Aparecido Leoti Zanetti² (willian.zanetti@unesp.br)

Bruno César Góes' (bruno.goes@unifenas.br)
\end{abstract}

\footnotetext{
${ }^{1}$ Universidade José do Rosário Vellano (UNIFENAS). Alfenas, MG, Brasil.

2 Universidade Estadual Paulista (UNESP). Tupã, SP, Brasil.
}

\begin{abstract}
RESUMO
A cultura de cana-de-açúcar é uma das principais fontes para produção de açúcar e etanol no Brasil, aferindo crescimento no setor, principalmente após a regulamentação dos veículos automotores flexfuel. Nesse sentido, o objetivo deste trabalho foi analisar o desempenho da área cultivada da cana-de-açúcar nos principais estados produtores: São Paulo, Goiás, Minas Gerais e Mato Grosso do Sul. Para análise dos dados de área e produção da cultura, foi considerado o período entre 2000 e 2020; já para produção de etanol e açúcar, foi considerado o período entre 2005 e 2020. Foi realizada a análise estatística de correlação de Pearson (r) entre as variáveis estudadas, durante o período de 2005 a 2020. Nesse sentido, foi possível observar o aumento da área plantada nas regiões analisadas, bem como o aumento da produtividade da cultura e do setor sucroalcooleiro, principalmente na região do Polígono do Agrohidronegócio, na região Centro-Sul do Brasil. A produção de etanol mostrou crescimento ao longo do período analisado, influenciado pelo aumento da produção de veículos flexfuel.
\end{abstract}

Palavras-chave: Açúcar. Agronegócio. Etanol. Tecnologia. 


\section{INTRODUÇÃO}

A cana-de-açúcar (Saccharum officinarum L.) é uma planta que possui alta capacidade para realização de fotossíntese, característica de plantas com metabolismo C4, ou seja, com alto poder de concentração de $\mathrm{CO}_{2}$ em função da redução da fotorrespiração, atingindo altas taxas de fotossíntese em elevada intensidade de radiação solar (LUCENA et al., 2020).

No Brasil, a produção da cultura da cana-de-açúcar destina-se principalmente para produção de açúcar e etanol, podendo ser obtidos outros produtos, tais como a cachaça artesanal, doces e forragens para tratar animais, sendo estas, realizadas em sua maioria por pequenos agricultores (PEREIRA et al., 2020).

Em muito a história do Brasil se entrelaça com a história da cultura da cana-deaçúcar no país, marcado por fatos relevantes sobre a expansão do setor sucroenergético, recebendo diversos investimentos tecnológicos na indústria sucroalcooleira e no campo em meados da década de 1970, com a criação do programa Proálcool (MATOS; MARAFON, 2020).

O Programa Nacional do Álcool (Proálcool) foi criado em 1975 em razão da elevação de preços do barril de petróleo. Porém, com a estabilização do preço do barril de petróleo, o problema de falta de gestão das usinas e a retirada dos subsídios, levou grande número de usinas a falência, interrompendo o programa (SILVA; POLI, 2020; BARCELOS, 2021).

Nesse sentido, o avanço do cultivo da cana-de-açúcar foi impulsionado pelo surgimento do primeiro veículo com motor flex-fuel (gasolina e álcool) em 2002, desenvolvido por empresas alemãs e produzido em série no Brasil a partir de março de 2003, onde desde então, os consumidores optam pelo abastecimento com etanol ou gasolina, ou pela mistura dos dois compostos, conforme for a variação dos preços dos combustíveis (EGESKOG et al., 2014; SANTOS; CASTILHO, 2020).

Sendo assim, em março de 2004, cerca de $16 \%$ dos veículos novos vendidos no Brasil já eram equipados com esse tipo de tecnologia, sendo em fevereiro de 2006, representavam cerca de 76,6\%, em novembro de 2007, 86,1\% e em 2010 esse percentual chegou a mais de 92\% (XAVIER, 2007; KOHLHEPP, 2010; BORDONAL, et al., 2018).

Com a demanda expressiva pelo etanol, houve grande expansão da área plantada da cultura da cana-de-açúcar, bem como o crescente número de usinas canavieiras espalhadas pelo território brasileiro, no qual, a região Sudeste possui cerca de 235 usinas, o Centro-Oeste 81 usinas, Nordeste 73 usinas, Sul 34 usinas e a Região Norte conta com 
5 usinas instaladas, sendo ao todo um total de 418 usinas distribuídas no Brasil (NOVACANA, 2021).

Em termos de área plantada o estado de São Paulo é o maior produtor da cultura ocupando o primeiro lugar com 4,5 milhões de hectares, em segundo o estado de Goiás com 971,6 mil hectares, Minas Gerais é o terceiro com 854,2 mil hectares e Mato Grosso do Sul é o quarto com 637,2 mil hectares. A produção de canavieira nos quatros estados na safra de 2020/2021 foi de 354,3 ,milhões de toneladas em São Paulo, 74,1 milhões de toneladas em Goiás, 70,5 em Minas Gerais e 48,9 milhões de toneladas em Mato Grosso do Sul (CONAB, 2021).

A previsão da produção nacional de cana-de-açúcar na safra de 2020/21 é de 654,53 mil toneladas em 8,62 mil hectares de área colhida, com produtividade média de 75.965 $\mathrm{kg} / \mathrm{ha}$. A produção de açúcar prevista é de 41.254 toneladas e o etanol hidratado terá produção de 22,5 bilhões de litros. A produção total de etanol incluindo o anidro, é de 32,8 bilhões de litros (CONAB, 2021).

O objetivo deste trabalho foi analisar o desempenho da área cultivada da cana-deaçúcar nos principais estados produtores: São Paulo, Goiás, Minas Gerais e Mato Grosso do Sul em razão dos principais produtos derivados, etanol e açúcar.

\section{MATERIAIS E MÉTODOS}

\subsection{VARIÁVEIS E FONTE DE DADOS}

Foram coletados dados sobre a produção da cultura de cana-de-açúcar, mensurados em mil toneladas e da área plantada, medida em mil hectares, referente aos principais estados produtores da cultura, sendo eles: São Paulo (SP), Minas Gerais (MG), Goiás (GO) e Mato Grosso do Sul (MS).

O levantamento dos dados sobre área e produção de cada estado foram coletados na base de dados da Empresa Brasileira de Pesquisa Agropecuária (EMBRAPA) e da Companhia Nacional de Abastecimento (CONAB) entre os anos de 2000 e 2020 . Por sua vez, os dados referentes a produção de açúcar e etanol foram coletados junto a base de dados do Instituto Brasileiro de Geografia e Estatística (IBGE) entre os anos de 2005 a 2020. 


\subsection{ANÁLISE DE DADOS}

Para tais análises estatísticas e elaboração gráfica, foram utilizados os softwares MINITAB $18^{\circledR}$ e SigmaPlot $14.0^{\circledR}$, respectivamente, sendo os mesmos, organizados em planilhas do Microsoft Office Excel ${ }^{\circledR} 2016$, para posterior confecção dos gráficos.

\subsection{ANÁLISE ESTATÍSTICA}

O procedimento estatístico utilizado para análise dos dados, fundamenta-se na análise da correlação de Pearson ( $r$ ) com a obtenção da matriz de correlação entre as variáveis analisadas, com base na significação de 5\% e 1\%, para p-valor, 0,01<p $\leq$ 0,05, e $p \leq 0,01$, respectivamente. Os valores do coeficiente de correlação de Pearson variam entre -1 e 1 , sendo classificados de acordo com a Tabela 1 a seguir.

Tabela 1 - Categorização para os valores do coeficiente de correlação de Pearson de acordo com Jacques Callegari.

\begin{tabular}{c|c|c}
\hline Coeficiente & Classificação & Tipo de Correlação \\
\hline$r=-1$ & Perfeita & Negativa \\
\hline$-1<r<-0,9$ & Muito Forte & Negativa \\
\hline$-0,9<r \leq-0,6$ & Forte & Negativa \\
\hline$-0,6<r \leq-0,3$ & Moderada & Negativa \\
\hline$-0,3<r \leq 0$ & Fraca & Nula \\
\hline$r=0$ & Nula & Positiva \\
\hline $0<r \leq+0,3$ & Fraca & Positiva \\
\hline$+0,3<r \leq+0,6$ & Moderada & Positiva \\
\hline$+0,6<r \leq+0,9$ & Forte & Positiva \\
\hline$+0,9<r<+1$ & Muito Forte & Positiva
\end{tabular}

Fonte: Adaptado de Callegari-Jacques (2009).

Nesse sentido, a correlação de Pearson mensura a força de interação entre duas variáveis quantitativas, conforme o grau da relação linear e direção dessas varáveis, sendo calculada da seguinte maneira (MOORE, 2007; FIGUEIREDO FILHO; SILVA JÚNIOR, 2009; GALARÇA et al., 2010). 


$$
r=\frac{\sum_{i=1}^{n}\left(x_{i}-\bar{x}\right)\left(y_{i}-\bar{y}\right)}{\sqrt{\sum_{i=1}^{n}\left(x_{i}-\bar{x}\right)^{2}} \cdot \sqrt{\sum_{i=1}^{n}\left(y_{i}-\bar{y}\right)^{2}}}
$$

- $x_{i}, y_{i}=$ valores medidos das respectivas variáveis;

- $\bar{x}, \bar{y}=$ média aritmética das variáveis analisadas.

Para a apresentação da matriz de correlação de Pearson, foram destacados os coeficientes que obtiveram valores com nível de significância de 1\% e 5\% de probabilidade de erro, sendo os coeficientes de correlação categorizados.

\section{RESULTADOS E DISCUSSÃO}

Observa-se o aumento da área colhida de 3,3 milhões de hectares em 2000 para mais de 5,6 milhões de hectares em 2009, representando um aumento de 69,7\% na área destinada ao cultivo da cultura da cana-de-açúcar, enquanto as áreas de cultivo de outras culturas se mantiveram inalteradas, conforme destaca Andrade, Carvalho e Souza (2009).

Ressalta-se nesse período o aumento da frota nacional de veículos automotores com a tecnologia flexfuel, impulsionou a retomada de grandes projetos e investimentos no setor sucroalcooleiro, no qual, a produção de automóveis da categoria flex foi de 49 mil unidades em 2003, em 2006 1,3 milhão, em 2009 2,54 milhões, em 2010 2,6 milhões, em 2013 2,95 milhões, em 2019 2,26 milhões e em 2020 1,53 milhão, de acordo com a Associação Nacional dos Fabricantes de Veículos Automotores (2021).

Considerando que a expansão da cultura ocorreu em todas as regiões produtoras observadas, conforme mostra a Figura 1, representado pela expansão tecnológica, infraestrutura e propensões de produção, configurando o estado de São Paulo como principal produtor e o estado de Goiás como segundo. Resultados que podem ser evidenciados e mostram esta tendência nos últimos levantamentos de safras. (CONAB 2021). 
Figura 1 - Dados da área plantada de cana-de-açúcar no período de 2000 a 2020.

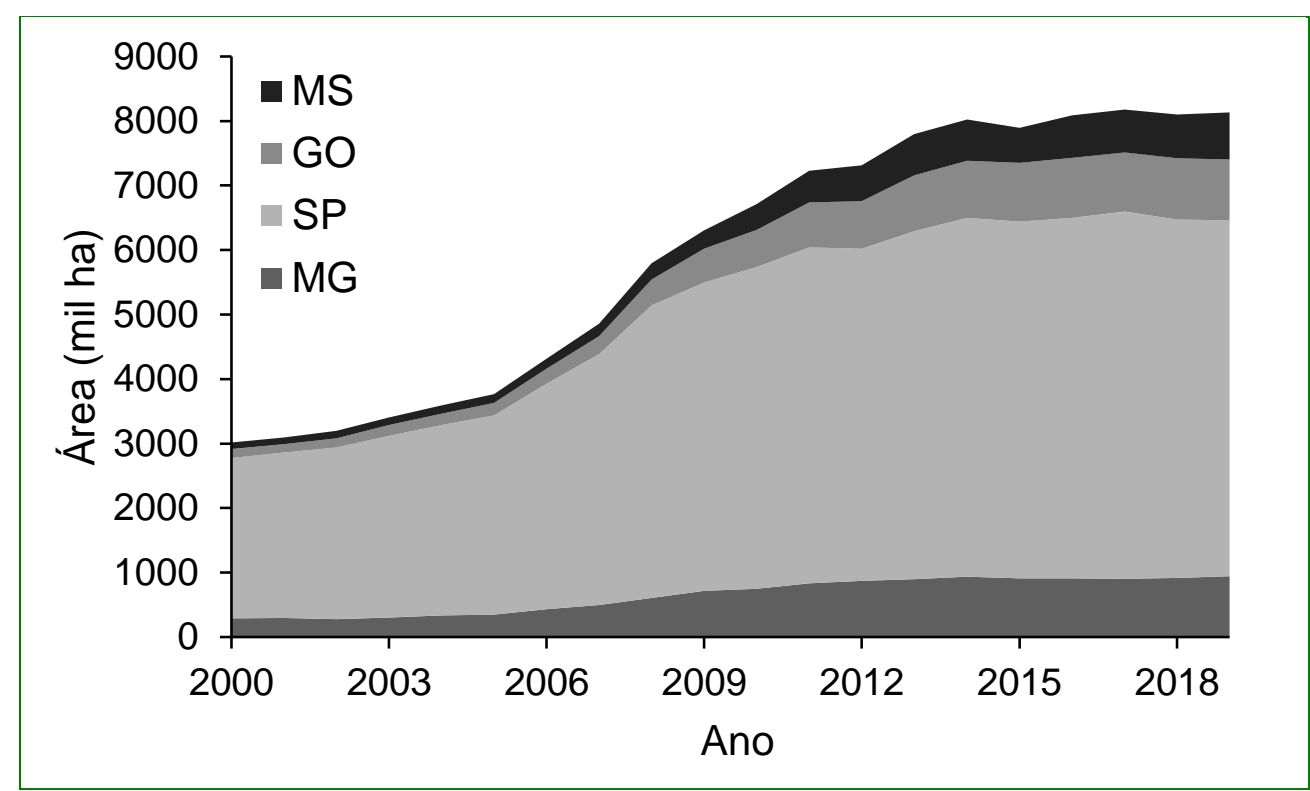

Fonte: Elaborada pelos próprios autores

Conforme o CEPEA (2020) o comportamento de aumento e diminuição de áreas plantadas pode ocorrer por vários fatores, desde a falta de continuidade do empreendimento à falta de acesso a novas tecnologias, reforma de lavouras entre outras. Nesse sentido, o incremento da tecnologia de veículos flex-fuel, aumentou a demanda pelo combustível derivado do processo da cana-de-açúcar, o etanol, impulsionando a produção da cultura de cana-de-açúcar aferindo crescimento nos quatros estados analisados durante o período analisado entre 2000 e 2020, no qual, atingiu em 2013 a produção de 2.951 .688 carros flex-fuel (ANFAVEA, 2021).

Porém, observando a produção de cana-de-açúcar no período de 2000 a 2020, conforme mostra a Figura 2, identifica que Minas Gerais apresentou um discreto crescimento da produção de cana-de-açúcar de 2,1\% na safra 2017/18, e na safra 2018/19 uma redução de $2,8 \%$ em relação à safra anterior, voltando a aferir um pequeno crescimento na safra de 2019/20 de 1,4\% em relação à safra passada (CONAB, 2018; 2019; 2020). 
Figura 2 - Dados da produção de cana-de-açúcar no período de 2000 a 2020.

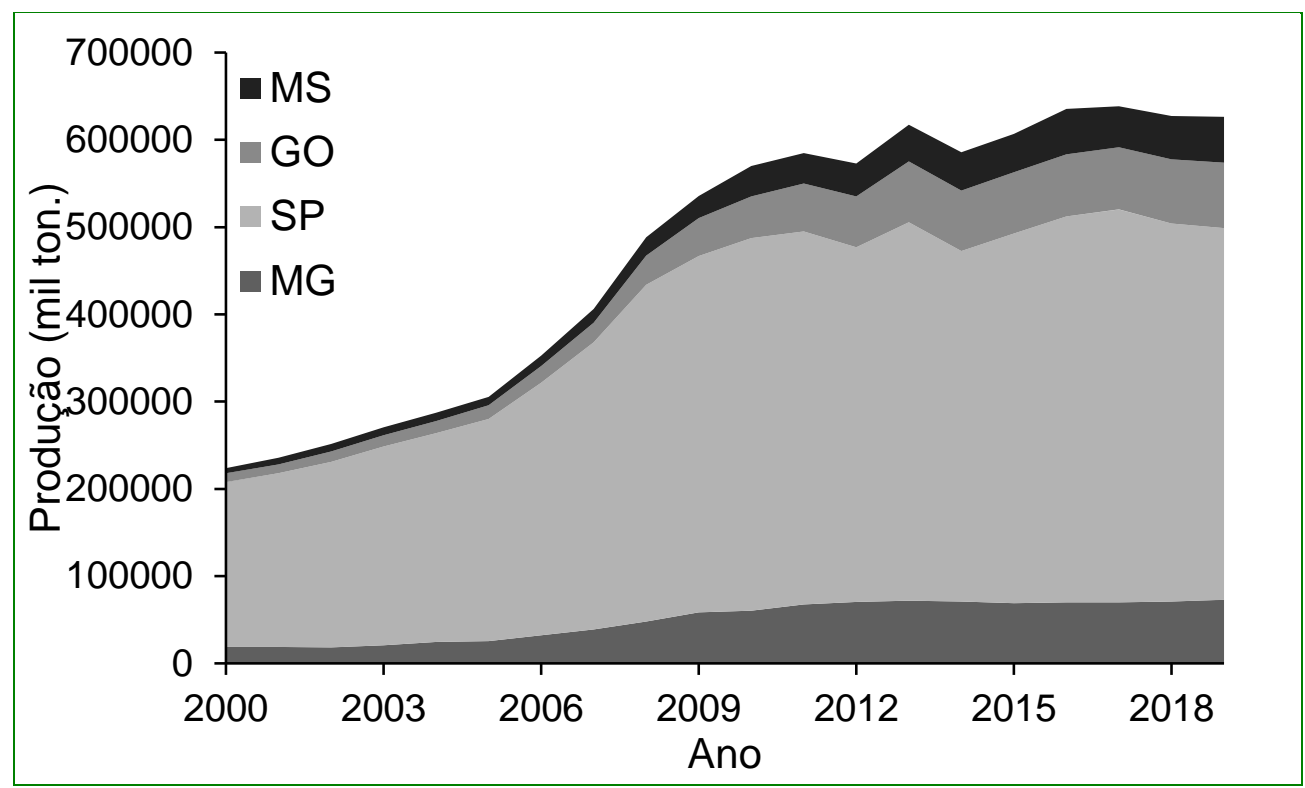

Fonte: Elaborada pelos próprios autores

É possível observar também que na safra de 2013/14 que Minas Gerais contribuiu com $13,5 \%$ na produção da região Centro-Sul e o estado registrou $18,7 \%$ em crescimento na produção de cana (CONAB, 2014). Tal elevação pode ter sido influenciada pela demanda do mercado externo e da produção de carros flexfuel.

Apesar dos dados mostrarem crescimento, vale ressaltar que entre os anos de 2005 a 2010, ocorreu grande expansão de quantidade produzida e de área colhida de canade-açúcar nos estados de Goiás e Mato Grosso do Sul, mostrando que o centro-oeste do Brasil despontou como nova fronteira da cana, no qual, o crescimento da produção na região neste período foi de $22 \%$ e a área colhida cresceu $17 \%$ ao ano, de acordo com Bittencourt e Gomes (2014).

Nesse sentido, foi realizada a matriz de correlação entre as variáveis analisadas, com base na significação de $5 \%$ e 1\%, conforme a Tabela 2 a seguir. 
Tabela 2 - Coeficiente de Correlação de Pearson entre as variáveis, área plantada e produção de cana-deaçúcar e as variáveis de produção de etanol e açúcar nos principais estados produtores.

\begin{tabular}{l|cccccccc}
\hline & $\mathbf{M G}$ área & $\mathbf{S P}$ área & $\mathbf{G O}_{\text {área }}$ & $\mathbf{M S}$ área & $\mathbf{M G}_{\text {pro }}$ & $\mathbf{S P}_{\text {pro }}$ & $\mathbf{G O}_{\text {pro }}$ & $\mathbf{M S}_{\text {pro }}$ \\
\hline $\mathbf{M G}_{\text {etanol }}$ & 0.870 & 0.879 & 0.876 & 0.840 & 0.847 & 0.831 & 0.887 & 0.896 \\
$\mathbf{S P}_{\text {etanol }}$ & - & 0.565 & - & - & - & 0.619 & - & - \\
$\mathbf{G O}_{\text {etanol }}$ & 0.952 & 0.938 & 0.987 & 0.969 & 0.919 & 0.84 & 0.985 & 0.986 \\
$\mathbf{M S}_{\text {etanol }}$ & 0.917 & 0.899 & 0.963 & 0.952 & 0.881 & 0.799 & 0.959 & 0.973 \\
$\mathbf{M G}_{\text {açúcar }}$ & 0.880 & 0.903 & 0.866 & 0.854 & 0.881 & 0.895 & 0.864 & 0.871 \\
$\mathbf{S P}_{\text {açúcar }}$ & 0.559 & 0.582 & - & - & 0.599 & 0.639 & - & - \\
$\mathbf{G O}_{\text {açúcar }}$ & 0.932 & 0.931 & 0.915 & 0.901 & 0.928 & 0.880 & 0.916 & 0.909 \\
$\mathbf{M S}_{\text {açúcar }}$ & 0.717 & 0.731 & 0.647 & 0.635 & 0.743 & 0.738 & 0.644 & 0.638 \\
\hline
\end{tabular}

Fonte: Elaborada pelos autores.

Observando que houve para o estado de Goiás e Mato Grosso do Sul uma maior expansão tanto em área plantada quanto em produção de cana-de-açúcar. No qual, fatores relacionados ao favorecimento do relevo para mecanização, disponibilidade de terras, créditos para implantação de usinas/destilarias em Goiás, podem estar relacionados a este crescimento, como exposto por Rossi e Fernandes (2020). Assim como as condições fisiográficas, infraestruturas, normativas legais favoráveis e custos, fizeram ter regiões competitivas no estado de Mato Grosso do Sul, tendo inseridas no chamado "Polígono do Agrohidronegócio" e na "Macrorregião Sucroenergética do Centro-Sul do Brasil" (SAMPAIO, 2021).

Minas Gerais também é outro estado que apresenta valores significativos que podem representar a expansão tanto em área plantada, como também em produção. Estado que em 2020 representou $11,1 \%$ da produção brasileira, com uma produção predominante localizada na Mesorregião do Triângulo Mineiro e Alto Paranaíba, com presença de infraestrutura agroindustrial e logística. No qual, o crescimento vem assegurado por meio de políticas públicas, além de solos e clima favoráveis (TAMBORIN; SANTOS, 2021).

No cenário do estado de São Paulo pode observar que os valores não foram significativos para expansão de área plantada, assim como teve pouca variação para a produção. Visto que esses resultados podem estar relacionados com a pouca variação no estado, em que o mesmo ainda se mantém como maior produtor da cultura, além de possuir grande avanço em tecnologias com maquinários e melhoramentos genético na busca por cultivares altamente produtivos (BEZERRA et al., 2018; KODAMA; LOURENZANI, 2021). 
De modo que, a demanda nacional e internacional por produtos derivados da canade-açúcar faz com que a produção oscile junto em busca de cenários com melhor rentabilidade para o setor. Em que resultados favoráveis de produção depende de diversos fatores como, climáticos, disponibilidade tecnológica, custo de produção, taxa de câmbio entre os parceiros, distância, logística e incentivos à produção (CRUZ et al., 2020).

Neste contexto, a Figura 3 expressa a evolução do cenário de produção de açúcar e etanol no período de 2005 a 2020.

Figura 3 - Produção de açúcar e etanol no período de 2005 a 2020.

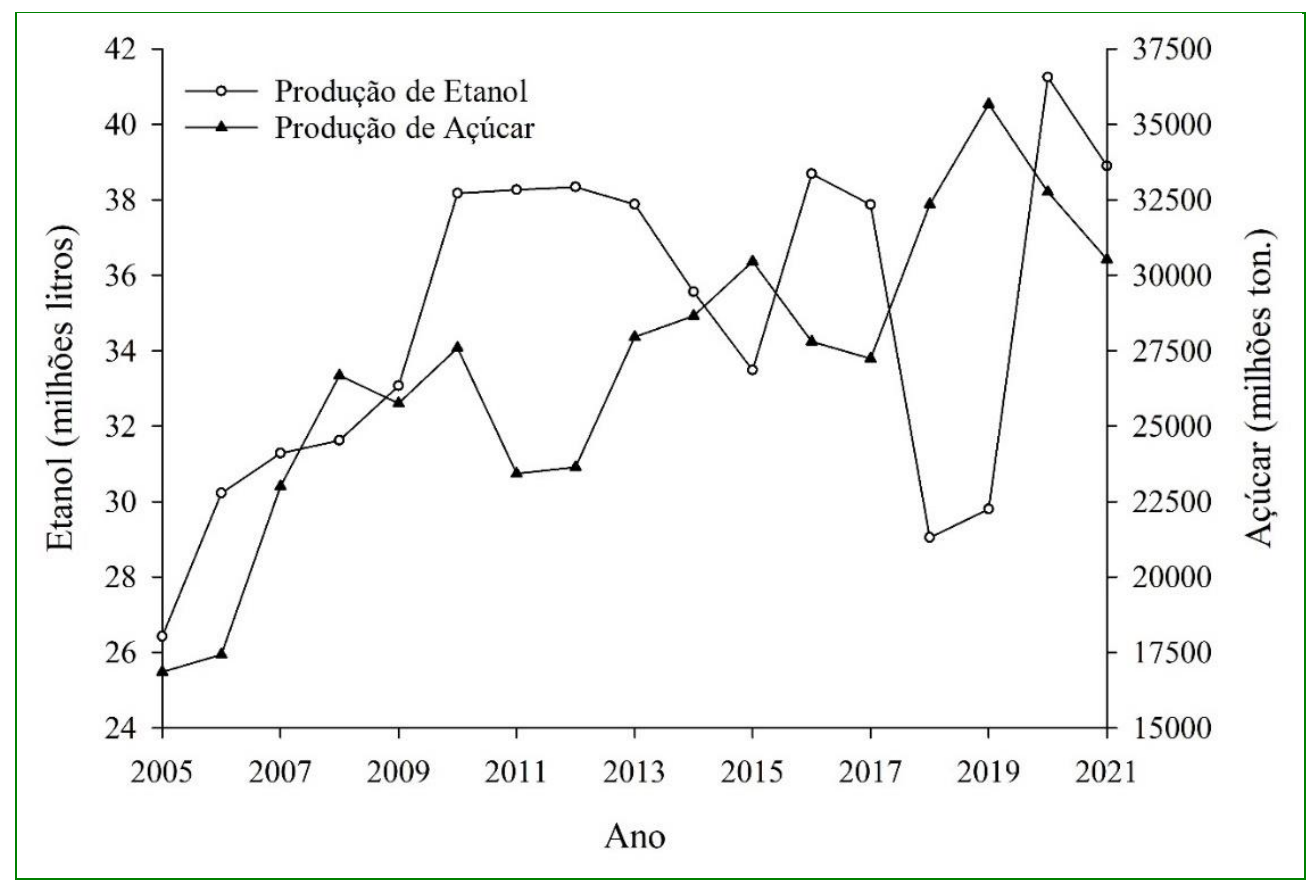

Fonte: Elaborada pelos próprios autores.

Evidenciando que a produção de açúcar e etanol alterna elevações e quedas nos quatros estados estudados entre 2000 e 2020, principalmente o açúcar mineiro (PEREIRA; BARRETO, 2020). Representando o período de 2017 a 2019 com grande diminuição de produção de etanol, caracterizado ainda pelo período em que o Brasil perdeu a posição de maior produtor mundial de cana-de-açúcar para a Índia, representado por diminuição de área cultivada e produção em virtude de crises hídricas, como evidenciado no trabalho de Araújo e Araújo Sobrinho (2020).

De forma que, o aumento da área, produção e exportação do setor sucroenergético no Brasil teve início no final da década de 90 e acelerou com os investimentos em usinas em 2003 movida pela demanda internacional, como também por fatores favoráveis estabelecido pelo Estado, como a implantação PRONAF Biodiesel concedido pelo 
Ministério do Desenvolvimento Agrário em 2008, e com o Programa de Apoio à Renovação e Implantação de Novos Canaviais (PRORENOVA) estabelecido pelo BNDES em 2013, promovendo melhores taxas de juros e promoção de financiamento (PAULI et al., 2020).

Impulsionado ainda pela demanda internacional de açúcar, adesão crescente ao etanol como biocombustível em carros flex, insegurança a oferta de combustíveis fósseis, preocupações ambientais, atrelado a necessidade de alternativa para a matriz energética brasileira (CRUZ; COELHO; TORRES, 2020).

Constando que a introdução de técnicas e a modernização no setor, desde melhorias nos tratos culturais até aperfeiçoamento nos controles operacionais, com a busca por melhor eficiência, resultaram em aspectos que permitiram uma expansão da cultura com a produção de etanol e açúcar, assegurando papel de grande importância no agronegócio brasileiro e na participação do Produto Interno Bruto (PIB) (ANDRADE, 2017; MUSSI et al., 2020).

\section{CONCLUSÕES}

Durante grande parte do período histórico, o Brasil se mantém na posição de um dos principais produtores e exportadores mundiais de açúcar, apesar de oscilações ocorridas no setor. No período entre 2003 e 2005, percebe-se que o cenário da área plantada, produção de açúcar e etanol é crescente, sofrendo influência direta do surgimento do veículo com motor flexfuel, além da mistura obrigatória de etanol na gasolina para redução de custos em razão da alta do preço do barril de petróleo no mercado. O total de veículos com a tecnologia flexfuel já representava cerca de 92\% da frota nacional no ano de 2010 .

Observando que a produção de cana-de-açúcar no país, estimulando principalmente pelos quatro estados com maior participação produtiva, apresenta uma evolução pautada principalmente por políticas públicas de incentivos para investimentos, desenvolvimento tecnológico, aporte à produção e exportação que asseguram um importante papel no desenvolvimento do agronegócio nacional.

\section{REFERÊNCIAS}

ANDRADE, M. C. Inovações tecnológicas no setor sucroalcooleiro: Determinantes, estágio vigente e perspectivas no contexto brasileiro (2005 - 2014). Revista Brasileira de Gestão e Inovação - Brazilian Journal of Management \& Innovation, v.4, n.3, p. 89106, 2017. 
ANFAVEA. Anuário da Indústria Automobilística Brasileira. Associação Nacional dos Fabricantes de Veículos Automotores ANFAVEA, v. 11, p.52-53. São Paulo, 2021.

ARAÚJO, D. F. C. de.; ARAÚJO SOBRINHO, F. L. A cultura agrícola da cana-de-açúcar no Brasil: contribuição ao estudo dos territórios rurais e suas contradições e conflitos.

Geopauta, v. 4, n. 1, p.162-183, 2020.

BARCELOS, M. Políticas de biocombustíveis no Brasil: uma análise da agenda do álcool combustível com base no papel das ideias e dos agentes. Campos Neutrais - Revista Latino-Americana de Relações Internacionais, v. 3, n. 1, p. 12-26, 2021.

BARROS, R. Energia para um novo mundo. Rio de Janeiro. Monte Castelo Ideias, 2007. $160 \mathrm{p}$.

BEZERRA, J. D. C.; FERREIRA, G. D. G.; OLIVEIRA, M. W. de.; CAMPOS, J. M. de. S.; ANDRADE, A. P. de.; NASCIMENTO JÚNIOR, J. R. S. do. Cana-de-açúcar:

Melhoramento genético e suas finalidades forrageiras. Nucleus Animalium, v.10, n.2, p. 131-147, 2018.

BITTENCOURT, G. M.; GOMES, M. F. M. Fontes de crescimento da produção de canade-açúcar no Sudeste e Centro-Oeste do Brasil. REDES - Revista de Desenvolvimento Regional, Santa Cruz do Sul, v. 19, n. 2, p. 182-201, 2014.

BORDONAL, R. O. et al. Sustainability of sugarcane production in Brazil. A review. Agronomy for Sustainable Development, v. 38, n. 13, p. 1-23, 2018.

BRASIL. Ministério da Agricultura, Pecuária e Abastecimento. Projeções do Agronegócio: Brasil 2018/19 a 2028/29 projeções de longo prazo / Ministério da Agricultura, Pecuária e Abastecimento. Secretaria de Política Agrícola. - Brasília: MAPA/ACE, 2019. 126 p.

CALLEGARI-JACQUES, S. M. Bioestatística: princípios e aplicações. Tradução, Artmed Editora, 2009.

CEPEA. Centro de Estudos Avançados em Economia Aplicada. Açúcar/Perspectiva 2020: Produção mundial pode se retrair, após duas temporadas. USP - Universidade de São Paulo, 2020.

CONAB. Companhia Nacional de Abastecimento. Acompanhamento da safra brasileira de cana-de-açúcar. v. 7 - Safra 2013/2014, n. 4 - Quarto levantamento, Brasília, p.1-14, 2014.

CONAB. Companhia Nacional de Abastecimento. Acompanhamento da safra brasileira de cana-de-açúcar. v. 7 - Safra 2017/2018, n. 1 - Primeiro levantamento, Brasília, p.1-58, 2018.

CONAB. Companhia Nacional de Abastecimento. Acompanhamento da safra brasileira de cana-de-açúcar. v. 7 - Safra 2019/2020, n. 4 - Quarto levantamento, Brasília, p.1-58, 2020. 
CONAB. Companhia Nacional de Abastecimento. Acompanhamento da safra brasileira de cana-de-açúcar: v. 7 - Safra 2020/2021, n. 4 - Quarto levantamento, Brasília, p.1-57, 2021.

CRUZ, A., COELHO, M., TORRES, D. Dinamismo e competitividade do Brasil nos mercados doméstico e internacional de açúcar. Revista de Política Agrícola, v. 9, n. 2, p. 119-139, 2020.

EMBRAPA. Melhoramento genético de cana-de-açúcar / Lizz Kezzy de Morais. Aracaju: Embrapa Tabuleiros Costeiros, 38 p. (Documentos / Embrapa Tabuleiros Costeiros, 2015.

FIGUEIREDO FILHO, D. B.; SILVA JÚNIOR, J. A. Desvendando os mistérios do coeficiente de Correlação de Pearson (r). Revista Política Hoje, v. 18, n. 1, p. 115-146, 2009.

GALARÇA, S. P. et al. Correlação de Pearson e análise de trilha identificando variáveis para caracterizar porta-enxerto de Pyrus communis L. Ciência e Agrotecnologia, v. 34, n. 4, p. 860-869, 2010.

KOHLHEPP, G. Análise da situação da produção de etanol e biodiesel no Brasil. Estudos Avançados, v. 68, n. 24, p. 223-253, 2010.

LUCENA, R, A, F.; DeMARTElaeRE, A. C. F.; PRESTON, H. A. F.; PRESTON, W.; FEITOSA, S. dos. S. F.; FERREIRA, A. dos. S.; SILVA, H. F. da; SANTOS, J. J. M. dos. Brazilian Journal of Development. v.6, n.9, p. 64881-64892, 2020.

MATOS, P. F. de; MARAFON, G. J. Dinâmica territorial do setor sucroenergético em Santa Vitória, Minas Gerais. Revista Campo-Território, v.15, n.37, p. 1-18, 2020.

MOORE, D. S. The Basic Pratice of Statistic. New Yorkm Freeman, 2007.

MUSSI, R. F.; ALVES JÚNIOR, J.; EVANGELISTA, A. W. P.; CASAROLI, D.; BATTISTI, R. Evapotranspiração da cana-de-açúcar estimada pelo algoritmo Safer. Irriga, v. 25, n. 2, p. 263-278, 2020.

NOVACANA. As usinas de Açúcar e Etanol do Brasil. 2021. Disponível em: https://www.novacana.com/usinas_brasil/estados. Acesso em: 15 maio 2021.

PAULI, R. I. P.; ZAJONZ, B. T.; SCHULZ, J. R. da. S.; FREITAS, C. A. de. A Segurança Alimentar e Nutricional (SAN) vem sofrendo restrições pela produção de biocombustíveis? Uma análise a partir do modelo de Zockun. Revista de Desenvolvimento Econômico, v. 2, n. 46, p.210-232, 2020.

PEREIRA, L. A. G.; BARRETO, J. B. Geografia das exportações de açúcar e de etanol no estado de Minas Gerais. Revista Campo-Território, v. 15, n. 36, p. 230-258, 2020.

PEREIRA, M. J.; SANTOS, R. L. dos; SILVA, C. J. C. da; ATAIDE, L. dos S. C.; SANTOS, R. V. de S.; MONTE, I. R. do; SILVA, I. C. da; SANTOS, J. A. dos; SANTOS, M. B. da. C. Development of sugarcane varieties under foliar application of Nitrogen. Research, Society and Development, v. 9, n. 8, p. 1-18, 2020. 
ROSSI, R. M.; FERNANDES, B. F. Análise estratégica da evolução dos custos de produção da cultura da cana-de-açúcar em Goiás. Custos e @gronegócio on line, v. 16, n. 3, p.256-289, 2020.

SANTOS, H. F. dos; CASTILLO, R. Vulnerabilidade territorial do agronegócio globalizado no Brasil: crise do setor sucroenergético e implicações locais. GEOUSP Espaço e Tempo (Online), v. 24, n. 3, p. 508-532, 2020.

SAMPAIO, M. de. A. P. Mato Grosso do Sul e suas zonas canavieiras: uma região de fronteira (1931-2020). Revista NERA, v. 24, n. 60, p. 175-20, 2021.

SHIKIDA, P. F. A.; SOUZA, E. C. Agroindústria canavieira e crescimento econômico local. Revista de Economia e Sociologia Rural. 2009, v. 47, n. 3. 2021, pp. 569-600.

SILVA, C. C. da; POLLI, S. A. O programa nacional de produção e uso do biodiesel PNPB e a atuação da agricultura familiar. Brazilian Journal of health Review, v. 3, n. 2, p. 3542-3555, 2020.

TAMBORIN, C. V.; SANTOS, R. J. Expansão do cultivo de cana de açúcar na microrregião de Uberaba e a produção de leite. Observatorium: Revista Eletrônica De Geografia, v.11, n.3, p.78-107, 2021.

XAVIER, M. The Brazilian sugarcane ethanol experience. Advancing Liberty from the Economy to Ecology, Issue analysis 3, p. 1-14, 2007. 


\begin{abstract}
The cultivation of sugarcane is one of the main sources for the production of sugar and ethanol in Brazil, measuring growth in the sector, especially after the regulation of flexfuel motor vehicles. In this sense, the objective of this work was to analyze the performance of the sugarcane cultivated area in the main producing states: São Paulo, Goiás, Minas Gerais and Mato Grosso do Sul. considered the period between 2000 and 2020; for ethanol and sugar production, the period between 2005 and 2020 was considered. Statistical analysis of the Pearson correlation ( $r$ ) was performed between the studied variables, during the period from 2005 to 2020. In this sense, it was possible to observe the increase of the planted area in the analyzed regions, as well as the increase in the productivity of the crop and of the sugar-alcohol sector, mainly in the region of the Polygon of Agrohidronegócio, in the CenterSouth region of Brazil. Ethanol production showed growth over the period analyzed, influenced by the increase in the production of flexfuel vehicles.
\end{abstract}

Keywords: Sugar. Agribusiness. Ethanol.Technology.

\title{
RESUMEN
}

El cultivo de la caña de azúcar es una de las principales fuentes para la producción de azúcar y etanol en Brasil, midiendo el crecimiento del sector, especialmente después de la regulación de los vehículos automotores flexfuel. En este sentido, el objetivo de este trabajo fue analizar el desempeño del área cultivada de caña de azúcar en los principales estados productores: São Paulo, Goiás, Minas Gerais y Mato Grosso do Sul. Considerado el período entre 2000 y 2020; para la producción de etanol y azúcar, se consideró el período entre 2005 y 2020. El análisis estadístico de la correlación de Pearson (r) se realizó entre las variables estudiadas, durante el período de 2005 a 2020. En este sentido, se pudo observar el incremento del área sembrada en las regiones analizadas, así como el aumento de la productividad del cultivo y del sector azúcar-alcohol, principalmente en la región del Polígono de Agrohidronegócio, en la región Centro-Sur de Brasil. La producción de etanol mostró un crecimiento durante el período analizado, influenciado por el incremento en la producción de vehículos flexfuel.

Palabras-clave: Azúcar. Agroindustria. Etanol. Tecnología. 


\section{LICENÇA DE USO}

Este é um artigo publicado em acesso aberto (Open Access) sob a licença Creative Commons Atribuição 4.0 Internacional (CC BY 4.0), que permite uso, distribuição e reprodução em qualquer meio, desde que o trabalho original seja corretamente citado. Mais informações em: http://creativecommons.org/licenses/by/4.0

\section{CONFLITO DE INTERESSES}

Os autores declaram que não há conflito de interesses neste trabalho.

\section{CONTRIBUIÇÕES AUTORAIS}

Autor 1: Responsável pela autoria de todo o texto.

Autor 2: Responsável pela coautoria de todo o texto.

Autor 3: Responsável pela coautoria de todo o texto.

Autor 4: Responsável pela elaboração dos resultados.

\section{COMO REFERENCIAR}

ALVES, Lázaro Quintino; FRANCO, Petrus Narciso; ZANETTI; Willian Aparecido Leoti; GÓES; Bruno César. Desempenho da produção da cultura de cana-de-açúcar nos principais estados produtores. Revista Brasileira de Engenharia de Biossistemas (Tupã), v. 15, n. 2, p. 303-317, 2021. DOI:

http://dx.doi.org/10.18011/bioeng2021v15n2p303-317.

\section{RESPONSABILIBADE EDITORIAL}

Prof. Dr. Fernando Ferrari Putti ${ }^{1}$, Prof. Dr. Paulo Sérgio Barbosa dos Santos ${ }^{1}$, Prof. Dr. Eduardo Festozo Vicente ${ }^{1}$ e Prof. Dr. Diogo de Lucca Sartori ${ }^{1}$

1 Universidade Estadual Paulista "Júlio de Mesquita Filho", FCE - Faculdade de Ciências e Engenharia, Tupã, SP, Brasil. 